\title{
Pengaruh Sistem Tanam Benih Langsung (TABELA), SRI (System of Rice Intensification) dan Konvensional terhadap Gulma dan Hasil Padi (Oryza sativa L.)
}

\section{Effect of Direct Seeding System, System of Rice Intensification, and Conventional to Weed and Rice Results ( Oryza sativa $L$.}

\author{
Dessy Sarfika Agustiany ${ }^{1}$ Hartadi $^{2}$ dan Soekarto ${ }^{2}$ \\ ${ }^{1}$ Dosen Program Studi Agroteknologi, Fakultas Pertanian, Universitas Jember \\ Jl. Kalimantan 37, Kampus Tegal Boto, Jember 68121 \\ E-mail: hartadi12081953@gmail.com
}

Diterima 22 Maret 2017/Disetujui 30 Mei 2017

\begin{abstract}
Production of rice in 2014 declined from the previous year, in 2013 rice production reached 71,279,709 tons, while in 2014 , rice production only reached 70,846,465 tons. The decline in rice production can be caused by the rice planting systems used by farmers. In Indonesia has been known some systems namely rice cropping system with direct seeding (seeded), SRI (System of Rice Intentification) and conventional systems. SRI included in the system of transplanting seedlings use intermittent irrigation system but unlike transplanting conventional systems that use inundation irrigation system on land or growing media. System of direct seeding is done by sowing seeds into wateredsoil conditions. Irrigation condition in each different cropping systems can cause the absence of the pest organisme. One organism whose presence is influenced by cropping systems is weed. The research was conducted on a pot medium using a randomized block design (RBD), which consists of 5 treatments and repeated 5 times. From the research all treatments used in this study, treatment cropping systems with conventional seedling age 16 days was the best treatment because the weed population was low and the number of tillers, number, panicle, panicle length, number of grains per panicle and weight of grain hadthe highest average compared with other treatments.
\end{abstract}

Keyword : Cropping systems, weeds, rice

\section{ABSTRAK}

Produksi padi pada tahun 2014 menurun dari tahun sebelumnya, tahun 2013 produksi padi mencapai 71.279 .709 ton, sedangkan pada tahun 2014 produksi padi hanya mencapai 70.846 .465 ton. Penurunan produksi padi dapat disebabkan oleh sistem tanam tanaman padi yang digunakan petani. Di Indonesia telah dikenal beberapa sistem tanam padi yaitu padi dengan sistem tanam benih langsung (tabela), SRI (System of Rice Intentification) dan sistem konvensional. SRI termasuk dalam sistem tanam pindah (tapin) bibit yang menggunakan sistem pengairan berselang namun berbeda dengan sistem tapin konvensional yang menggunakan sistem pengairan penggenangan pada lahan atau media tanam. Sistem tanam benih langsung dilakukan dengan cara menyemai benih ke lahan dengan kondisi air pada lahan macak-macak. Kondisi pengairan pada masing-masing sistem tanam yang berbeda menyebabkan adanya OPT. Salah satu OPT yang keberadaannya dipengaruhi oleh sistem tanam yaitu gulma. Penelitian ini dilaksanakan pada media pot menggunakan Rancangan Acak Kelompok (RAK) yang terdiri dari 5 perlakuan yang diulang sebanyak 5 kali. Dari hasil penelitian semua perlakuan yang digunakan dalam penelitian ini, perlakuan sistem tanam konvensional dengan umur bibit 16 hari merupakan perlakuan yang terbaik dikarenakan populasi gulma yang rendah serta jumlah anakan, jumlah, malai, panjang malai, jumlah bulir per malai dan berat gabah tanaman padi memiliki rerata yang tertinggi dibandingkan dengan perlakuan yang lain.

Kata Kunci : Sistem tanam, gulma, hasil padi

\section{PENDAHULUAN}

Negara Indonesia merupakan negara agraris yang mayoritas masyarakatnya bertani atau bercocok tanam guna memenuhi dan mencukupi kebutuhan pangan. Tanaman pangan yang sering dibudidayakan salah satunya yaitu padi.
Budidaya tanaman padi di sebagian besar wilayah Indonesia menjadikan hasil dari tanaman padi berupa beras sebagai makanan utama masyarakat Indonesia. Kebutuhan beras dari tahun ke tahun semakin meningkat, namun hal ini tidak sesuai dengan ketersediaan beras yang ada di pasar. Produksi padi pada tahun 2014 menurun dari tahun 
sebelumnya. Tahun 2013 produksi padi mencapai 71.279.709 ton, sedangkan pada tahun 2014 produksi padi hanya mencapai 70.846.465 ton (Badan Pusat Statistik, 2015). Penurunan produksi padi dapat disebabkan oleh sistem tanam tanaman padi yang digunakan petani sesuai dengan pendapat Aruan dan Rita (2010) yang menyatakan bahwa sistem tanam dalam budidaya padi akan mempengaruhi hasil produksi padi.

Di Indonesia telah dikenal beberapa sistem tanam padi yaitu padi dengan sistem tanam benih langsung (tabela), SRI (System of Rice Intentification) dan sistem konvensional. SRI termasuk dalam sistem tanam pindah (tapin) bibit namun berbeda dengan sistem tapin konvensional yang menggunakan sistem pengairan penggenangan pada lahan atau media tanam. Sistem tanam benih langsung dilakukan dengan cara menyemai benih ke lahan dengan kondisi air pada lahan macak-macak. Herawati (2012) menyatakan bahwa sistem SRI (System of Rice Intentification) mempunyai beberapa prinsip yaitu tanaman bibit muda berusia kurang dari 12 hari ketika bibit masih berdaun 2 helai, bibit ditanam secara tunggal atau satu bibit per lubang tanam dengan jarak $30 \times 30 \mathrm{~cm}$, pemberian air pada metode SRI yaitu maksimal $2 \mathrm{~cm}$ (macak-macak) secara berselang, pemupukan menggunakan pupuk organik (kompos atau pupuk hijau) namun hal ini tidak diharuskan. Sistem tanam tapin secara konvensional dilakukan dengan cara menyemai benih yang sudah disemaikan terlebih dahulu maksimal 25 hari lalu memindahkannya ke lahan dengan kondisi lahan tergenang.

Penggunaan sistem tanam tanaman padi yang beragam merupakan salah satu upaya untuk meningkatkan produksi beras agar kebutuhan akan beras dapat terpenuhi. Menurut Fisheer (1998) dalam Badan Penelitian Tanah (2011) produksi padi

pada sistem SRI mampu memberikan hasil padi antara 7-12 ton/ha. Produksi padi pada sistem konvensional menurut Wulandari dan Syam (2007) dalam Badan Penelitian Tanah (2011) dapat menghasilkan padi rata-rata 4,77 ton/ha. Sistem tabela dapat menghasilkan produksi padi antara 7-8,2 ton/ha.

Upaya ini tidak sesuai dengan yang diharapkan karena dapat menimbulkan adanya OPT (Organisme Pengganggu Tumbuhan) yang dapat menyerang tanaman. Keberadaan OPT juga dapat dipengaruhi oleh sistem tanam yang digunakan. Salah satu OPT yang keberadaannya dipengaruhi oleh sistem tanam yaitu gulma. Gulma merupakan organisme pengganggu tumbuhan (OPT) yang hidup disekitar tanaman pokok atau tanaman yang sengaja dibudidayakan. Tjitrosoedirdjo et al. (1984) dalam Pandia (2011) menyatakan bahwa keberadaan gulma pada areal produksi pertanian dapat menimbulkan kerugian hasil baik secara kualitas maupun kuantitas. Penurunan hasil tanaman akibat keberadaan gulma disebabkan oleh adanya kompetisi antara gulma dengan tanaman dalam memperoleh air, unsur hara, cahaya dan ruang tumbuh.

Penelitian ini akan menguji sistem tanam tanaman padi yaitu sistem tabela, SRI (System of Rice Intentification) dan sistem konvensional terhadap gulma dan produksi padi. Penelitian ini dilakukan di pot guna mendapatkan data sesuai dengan variabel penelitian yang nantinya dapat digunakan sebagai pertimbangan penggunaan sistem tanam padi di lahan berkaitan dengan keberadaan gulma dan hasil padi. Pemilihan sistem tanam yang tepat dalam budidaya tanaman padi bertujuan untuk meningkatkan produksi padi dan juga sebagai upaya penanggulangan dan pengendalian OPT yaitu gulma yang dapat menurunkan hasil padi

\section{BAHAN DAN METODE}

\section{Waktu dan tempat}

Penelitian ini dilaksanakan dalam media pot kemudian diletakkan di Desa Jember Lor Kecamatan Patrang Kabupaten Jember yang dilaksanakan pada bulan November 2015 sampai April 2016. Percobaan ini menggunakan Rancangan Acak Kelompok (RAK) yang terdiri dari 5 perlakuan sebagai berikut :A1 merupakan sistem tanam benih langsung (tabela); A2 merupakan sistem tanam pindah (tapin) metode SRI dengan benih berumur 7 hari; A3 merupakan sistem tanam pindah (tapin) metode SRI dengan benih berumur 10 hari; A4 merupakan sistem tanam pindah (tapin) metode konvensional dengan benih berumur 13 hari dan A5 merupakan sistem tanam pindah (tapin) metode konvensional dengan benih berumur 16 hari. Masing-masing perlakuan diulang sebanyak 5 kali.

\section{Pelaksanaan Penelitian}

\subsection{Penyiapan Penelitian}

Penelitian ini menggunakan beberapa alat dan bahan. Alat-alat yang digunakan dalam penelitian ini yaitu nampan, pot, cangkul, meteran dan ember. Bahan-bahan yang digunakan dalam penelitian ini yaitu benih padi, air, pupuk organik, pupuk urea, pupuk SP-36, pestisida.

\subsection{Penyiapan benih dan persemaian}

Persemaian benih secara langsung pada media pot dilakukan untuk sistem tanam tabela. Perlakuan sistem tapin metode SRI dan sistem tapin secara metode konvensional dilakukan dengan memilih benih yang bernas dengan cara memasukkan benih padi ke dalam larutan garam dapur dengan konsentrasi $200 \mathrm{~g} / \mathrm{l}$, benih padi yang tenggelam merupakan benih padi yang bernas. Benih padi bernas selanjutnya diambil dan dibilas dengan air tawar agar larutan garamnya hilang. Kemudian melakukan perendaman benih padi bernas ke dalam air bersih selama 48 jam dan pemeraman selama 48 jam. Benih kemudian disemaikan di atas nampan yang telah terisi campuran media tanam tanah dengan kompos dengan perbandingan 1:1.

\subsection{Penyiapan media tanam dan penanaman}

Persiapan media dilakukan dengan cara mengambil tanah di lahan sawah yang telah dilakukan penanaman padi secara terus menerus kemudian mengisi pot dengan tanah sawah tersebut sebagai media tanam padi. Melakukan penanaman bibit untuk perlakuan A2, A3, A4 dan A5, 
sedangkan untuk perlakuan A1 dilakukan dengan cara menyemai benih padi pada pot. Masing-masing pot diberi 3 bibit atau benih sesuai dengan perlakuan.

\subsection{Pemupukan}

Pemupukan dilakukan selama tiga kali yaitu pada 7 hari HST (hari setelah tanam) dengan pupuk Urea dan SP36, pada umur 25 HST dengan Urea dan pada umur 40 HST.

\subsection{Pemeliharaan tanaman}

Pemeliharaan tanaman dilakukan dengan pengairan yaitu penggenangan maksimal $2-5 \mathrm{~cm}$ diatas permukaan tanah untuk perlakuan A4 dan A5. Menurut Antralina et al. (2014) dari aspek pengelolaan air, usaha tani sawah secara konvensional pada umumnya dilakukan dengan penggenangan secara terus - menerus. Perlakuan A1 menggunakan sistem pengairan macak - macak yaitu kondisi air pada lahan atau media tanam sebaiknya dikondisikan macak - macak hingga benih tumbuh 10 hari kemudian pemberian air disesuaikan dengan ketinggian tanaman dengan kondisi macak-macak atau lembab. Perlakuan A2 dan A3 yaitu tapin metode SRI menggunakan sistem pengairan intermittern (Harjanti, 2012) yaitu :

- Tanam bibit dalam kondisi media yang digunakan macak-macak.

- Pergiliran air dilakukan selang 3-5 hari, tinggi genangan pada hari pertama $3 \mathrm{~cm}$ dan media tanam diairi lagi pada hari ke 5. Cara pengairan ini berlangsung sampai fase anakan maksimal yaitu sampai dengan 41 HST.

- Media tanam digenangi terus mulai fase pembentukan malai sampai pengisian biji yaitu 41-90 HST.

- Sekitar 10-15 hari sebelum panen, media tanam dikeringkan.

Selain itu melakukan pengendalian hama dan penyakit tanaman padi.

\subsection{Pemanenan}

Kegiatan ini dilakukan setelah tanaman menunjukkan kondisi masak fisiologis, yaitu ketika tanaman padi mulai menguning.

\section{Variabel Pengamatan}

\subsection{Gulma}

a. Populasi gulma

Mengamati, mencatat serta menghitung gulma yang termasuk golongan gulma berdaun lebar, gulma golongan rumput dan gulma golongan teki yang dilakukan 1 minggu setelah tanam (MST), 2 MST, 3 MST, 4 MST dan 5 MST.

b. Biomassa Gulma

Menghitung biomassa gulma. Mengambil gulma pada semua perlakuan dan ulangan setelah 35 HST. Mengelompokkan gulma berdasarkan golongannya kemudian dikering anginkan. Memasukkan ke dalam amplop yang terbuat dari kertas koran selanjutnya gulma tersebut dikeringkan pada temperatur $80{ }^{0} \mathrm{C}$ selama 48 jam atau sampai mencapai bobot kering konstan, kemudian ditimbang (Syahputra dan Sarbino 2012).

\subsection{Produksi padi}

a. Jumlah anakan tanaman padi. Menghitung jumlah anakan yang tumbuh pada semua perlakuan dan ulangan.

b. Jumlah malai tanaman padi. Menghitung jumlah malai pada semua perlakuan dan ulangan.

c. Panjang malai tanaman padi. Mengukur dan menghitung rata-rata panjang malai pada semua perlakuan dan ulangan.

d. Jumlah bulir per malai tanaman padi. Menghitung rata-rata jumlah bulir per malai pada semua perlakuan dan ulangan.

e. Produksi tanaman padi. Menimbang produksi tanaman padi pada semua perlakuan dan ulangan.

\subsection{Analisis data.}

Hasil penelitian dianalisis dengan sidik ragam (ANOVA), jika hasilnya berbeda nyata maka dilanjutkan dengan uji Duncan Multiple Range Test (DMRT) dengan taraf $5 \%$.

\section{HASIL DAN PEMBAHASAN}

\section{Hasil Sidik Ragam}

Hasil sidik ragam pada variabel pengamatan disajikan pada Tabel 1. Berdasarkan Tabel 1. diketahui pengaruh sistem tanam pada penelitian ini tidak berpengaruh terhadap jumlah anakan dan panjang malai tanaman padi. Selanjutnya hasil sidik ragam variabel pengamatan yang berpengaruh nyata diuji lanjut menggunakan uji DMRT dengan taraf 5\%.

\section{Populasi Gulma Berdaun Lebar, Rumput dan Teki}

Sistem tapin metode konvensional dengan umur bibit 16 hari berpengaruh dalam menekan populasi gulma dengan populasi gulma terendah dari semua perlakuan, hal ini disebabkan pada perlakuan sistem tapin metode konvensional dengan umur bibit 16 hari kondisi media tanam dalam keadaan tergenang. Pengelolaan air pada sistem tanam pindah secara konvensional pada umumnya dilakukan dengan penggenangan secara terus-menerus, hal ini merupakan salah satu upaya untuk mengendalikan gulma. Antralina et al. (2014) menyatakan bahwa kondisi tanah yang tergenangi menciptakan suasana anaerob sehingga perkecambahan biji gulma dapat dihambat. Penggenangan juga meyebabkan penghambatan suplai oksigen pada proses respirasi di sekitar perakaran sehingga penetrasi cahaya sinar matahari tinggi akibatnya merangsang perkecambahan bijibiji gulma yang dorman di dalam tanah. 


\section{Biomassa Gulma}

Perlakuan sistem tabela memiliki biomassa gulma yang tertinggi dari semua perlakuan baik pada gulma berdaun lebar, rumput dan teki. Biomassa gulma yang tinggi juga disebabkan oleh banyaknya hara, nutrisi dan air yang diserap oleh gulma tersebut sesuai dengan pernyataan Tjitroesoedirdjo et. al. (1984) dalam Pandia (2011) yang menjelaskan bahwa semakin tinggi tingkat pertumbuhan dan kerapatan gulma, maka tingkat persaingan padi dengan gulma terhadap faktor tumbuh semakin tinggi pula, terutama terhadap perolehan hara dari dalam tanah.

Tabel 1. Rangkuman Fhitungpada Berbagai Variabel Penelitian

\begin{tabular}{llc}
\hline No. & Variabel Penelitian & Nilai F-Hitung 5\% \\
\hline 1. & Populasi Gulma Berdaun Lebar 5 MST & $31.52^{*}$ \\
2. & Populasi Gulma Rumput 5 MST & $15.90^{*}$ \\
3. & Populasi Gulma Teki 5 MST & $129.31^{*}$ \\
4. & Biomassa Gulma Berdaun Lebar & $5.44^{*}$ \\
5. & Biomassa Gulma Rumput & $4.55^{*}$ \\
6. & Biomassa Gulma Teki & $31.62^{*}$ \\
7. & Jumlah Anakan Tanaman Padi & 0.06 tn \\
8. & Jumlah Malai Tanaman Padi & $14.01^{*}$ \\
9. & Panjang Malai Tanaman Padi & $2.44 \mathrm{tn}$ \\
10. & Jumlah Bulir Per Malai Tanaman Padi & $4.23^{*}$ \\
11. & Produksi Tanaman Padi & $3.61^{*}$ \\
\hline
\end{tabular}

Keterangan : berbeda tidak nyata (tn) dan berbeda nyata $(*)$

Tabel 2. Pengaruh Perlakuan terhadap Populasi Gulma Berdaun Lebar, Rumput dan Teki pada Minggu ke-5 Setelah Tanam

\begin{tabular}{cccc}
\hline Perlakuan & Gulma Berdaun Lebar & Rumput & Teki \\
\hline A1 & $57,00 \mathrm{a}$ & $11,60 \mathrm{a}$ & $31,80 \mathrm{a}$ \\
A2 & $54,00 \mathrm{a}$ & $9,80 \mathrm{a}$ & $31,60 \mathrm{a}$ \\
A3 & $53,00 \mathrm{a}$ & $9,40 \mathrm{a}$ & $30,80 \mathrm{a}$ \\
A4 & $19,80 \mathrm{~b}$ & $4,80 \mathrm{~b}$ & $3,80 \mathrm{~b}$ \\
A5 & $12,80 \mathrm{~b}$ & $4,20 \mathrm{~b}$ & $1,20 \mathrm{c}$ \\
\hline
\end{tabular}

Keterangan : Angka-angka yang diikuti huruf sama pada kolom yang sama menunjukkan tidak berbeda nyata berdasarkan Uji Jarak Ganda Duncan dengan taraf kepercayaan 5\%.

Tabel 3. Pengaruh Pelakuan terhadapBiomassa Gulma (gram)

\begin{tabular}{cccc}
\hline Perlakuan & Gulma Berdaun Lebar & Gulma Rumput & Gulma Teki \\
\hline A1 & $1,16 \mathrm{a}$ & $2,30 \mathrm{a}$ & $3,82 \mathrm{a}$ \\
A2 & $1,15 \mathrm{a}$ & $1,27 \mathrm{ab}$ & $2,53 \mathrm{a}$ \\
A3 & $0,97 \mathrm{ab}$ & $1,15 \mathrm{~b}$ & $2,83 \mathrm{a}$ \\
A4 & $0,49 \mathrm{bc}$ & $0,81 \mathrm{~b}$ & $0,19 \mathrm{~b}$ \\
A5 & $0,29 \mathrm{c}$ & $0,68 \mathrm{~b}$ & $0,01 \mathrm{~b}$ \\
\hline
\end{tabular}

Keterangan : Angka-angka yang diikuti huruf sama pada kolom yang sama menunjukkan tidak berbeda nyata berdasarkan Uji Jarak Ganda Duncan dengan taraf kepercayaan $5 \%$.

Tabel 4. Pengaruh Perlakuan terhadapJumlah Anakan, Komponen Hasil dan Hasil Padi 


\begin{tabular}{cccccc}
\hline Perlakuan & Jml. Anakan & Jml. Malai & Pjg Malai $(\mathrm{cm})$ & Jml. Bulir/malai & Berat Gabah $(\mathrm{g})$ \\
\hline A1 & $61,20 \mathrm{a}$ & $34,00 \mathrm{c}$ & $19,31 \mathrm{a}$ & $71,40 \mathrm{~b}$ & $47,68 \mathrm{~b}$ \\
A2 & $61,40 \mathrm{a}$ & $42,00 \mathrm{~b}$ & $19,31 \mathrm{a}$ & $75,60 \mathrm{ab}$ & $48,21 \mathrm{~b}$ \\
A3 & $61,60 \mathrm{a}$ & $45,40 \mathrm{ab}$ & $19,33 \mathrm{a}$ & $77,00 \mathrm{a}$ & $50,16 \mathrm{~b}$ \\
A4 & $62,20 \mathrm{a}$ & $46,80 \mathrm{ab}$ & $19,38 \mathrm{a}$ & $77,80 \mathrm{a}$ & $53,40 \mathrm{ab}$ \\
A5 & $64,60 \mathrm{a}$ & $47,80 \mathrm{a}$ & $19,47 \mathrm{a}$ & $78,60 \mathrm{a}$ & $58,33 \mathrm{a}$ \\
\hline
\end{tabular}

Keterangan : Angka-angka yang diikuti huruf sama pada kolom yang sama menunjukkan tidak berbeda nyata berdasarkan Uji Jarak Ganda Duncan dengan taraf kepercayaan 5\%

Perlakuan sistem tapin metode konvensional dengan umur bibit 16 hari mampu menekan pertumbuhan gulma yang memiliki biomassa gulma terendah dibandingkan dengan perlakuan sistem tanam yang lain disebabkan oleh kerapatan atau populasi gulma yang rendah sehingga hara, nutrisi dan air yang diserap oleh gulma relatif sedikit dikarenakan populasi gulma yang rendah.

\section{Hasil Tanaman Padi}

Kerapatan atau populasi gulma yang semakin tinggi menyebabkan persaingan antara gulma dengan tanaman padi meningkat sehingga dengan sistem tabela yang kondisi pengairannya macak-macak menyebabkan kebutuhan air pada tanaman padi sangat terbatas. Perlakuan sistem tapin metode konvensional dengan umur bibit 16 hari berpengaruh terhadap jumlah anakan lebih tinggi dibandingkan dengan semua perlakuan, hal ini sesuai dengan penelitian Lita et al. (2013) yang menunjukkan bahwa perlakuan dengan sistem tabela menunjukkan hasil jumlah anakan yang paling sedikit dibanding perlakuan sistem tanam konvensional, tabela dan SRI. Perlakuan sistem tapin metode konvensional dengan umur bibit 16 hari berpengaruh terhadap jumlah malai tertinggi. Jumlah malai pada masing-masing perlakuan tidak sama dengan jumlah anakan, keberadaan gulma menyebabkan tanaman padi tidak dapat menyerap kebutuhan hara, air dan nutrisi secara maksimal sehingga anakan yang produktif lebih sedikit dibandingkan dengan keseluruhan jumlah anakan.

Berat gabah tanaman padi menunjukkan hasil produksi pada setiap perlakuan. Perlakuan sistem tabela menunjukkan berat gabah yang terendah dari semua perlakuan, sedangkan perlakuan sistem tapin metode konvensional dengan umur bibit 16 hari memiliki berat gabah yang tertinggi. Jumlah gabah isi per malai akan menentukan produktifitas tanaman tersebut apabila malai yang terbentuk banyak menghasilkan padi yang bernas, maka produktifitas tanaman padi tinggi. Pernyataan tersebut didukung oleh Wibowo (2010) yang menyatakan bahwa jumlah gabah ditentukan oleh banyaknya jumlah anakan produktif dan umur berbunga lebih awal, dimana penyerbukan akan berhasil dan menghasilkan banyak padi yang bernas.

Populasi gulma pada masing-masing perlakuan menyebabkan perbedaan terhadap berat gabah. Berat gabah yang rendah disebabkan oleh populasi gulma disekitar tanaman padi menyebabkan adanya persaingan untuk mendapatkan hara, nutrisi dan air sesuai dengan pernyataan Merpaung et al. (2013) yaitu jumlah gabah hampa dan gabah isi per malai menunjukkan bahwa perlakuan kerapatan, pengendalian gulma serta interaksi antara kerapatan gulma dan pengendalian gulma berpengaruh nyata terhadap gabah hampa dan gabah isi per malai. Penggunaan sistem tanam padi dan teknik pengendalian gulma merupakan upaya untuk meningkatkan hasil produksi tanaman padi

\section{KESIMPULAN}

Berdasarkan hasil dari penelitian ini maka dapat disimpulkan bahwa sistem tanam konvensional dengan umur bibit 16 hari dapat menekan populasi dan biomassa gulma serta mampu meningkatkanjumlah malai, jumlah bulir per malai dan berat gabah.

\section{DAFTAR PUSTAKA}

Antralina, M., Yuyun Y. dan Tualar S. 2014. Komposisi Gulma Pada Berbagai Jarak Tanam Padi Secaran IPAT-BO dan Konvensional. Agro, 1(1):14-21.

Aruan, Y. L. dan Rita M. 2010. Perbandingan Pendapatan Usahatani Padi (Oryza sativa L.) Sawah Sistem Tanam Pindah dan Tanam Benih Langsung di Desa Sidomulyo Kecamatan Anggana Kabupaten Kutau Kartanegara. EPP, 7(2): 30-36.

Badan Penelitian Tanah. 2011. Analisis Komparatif Sistem Pertanian Konvensional,PTT dan SRI di Lahan Sawah Irigasi Jawa Baratterhadap Keseimbangan Hara, Dinamika Biologi,Efisiensi Pupuk (> 30\%) dan Nilai Ekonomi Usahatani. Bogor: Balai Besar Penelitian dan Pengembangan Sumber daya Lahan Pertanian.

Badan Pusat Statistik. 2015. Produksi Padi Menurut Provinsi 2011-2015. http://www.pertanian.go.id/ap_pages/mod/datatp. Diakses tanggal 19 Desember 2016.

Harjanti, R. A. 2012. Sistem Pengairan Intermittern pada System Rice Of Intensification (SRI) terhadap Pertumbuhan dan Hasil Padi (Oryza sativa L.).Yogyakarta: Fakultas Pertanian Universitas Gadjah Mada.20 hal.

Herawati, L. 2012. Dampak Budidaya Padi Organik dengan Metode SRI (System of Rice Intentification) terhadap Sustainabilitas Kandungan C Organik Tanah dan Pendapatan Usahatani Padi di Kecamatan Gunung 
Sugih Kabupaten Lampung Tengah. Tesis. Lampung: Lingkungan Universitas Lampung. 101 hal.

Lita, N. T., Sardjono S. dan Bambang G. 2013. Pengaruh Perbedaan Sistem Tanam Terhadap Pertumbuhan Dan Hasil Tanaman Padi (Oryza sativa L.) Di Lahan Sawah. Produksi Tanaman, 1(4): 361-368.

Marpaung, I. S., Yakup P. dan Erizal S. 2013. Evaluasi Kerapatan Tanam dan Metode Pengendalian Gulma pada Budidaya Padi Tanam Benih Langsung di Lahan Sawah Pasang Surut. Lahan Suboptimal, 2(1): 93-99.

Pandia, J. A. 2011. Aplikasi Herbisida Dalam Persiapan Lahan dan Frekuensi Pengendalian Gulma terhadap
Magister

Ilmu

Pertumbuhan dan Produksi Jagung (Zea mays L.). Bogor : Institut Pertanian Bogor. 46 hal.

Syahputra, E dan Sarbino. 2012. Keefektifan Parakuat Diklorida sebagai Herbisida untuk Persiapan Tanam Padi tanpa Olah Tanah di Lahan Pasang Surut. Perkebunan \& Lahan Tropika, 2(1): 15-22.

Wibowo, P. 2010. Pertumbuhan dan Produktivitas Galur Harapan Padi (Oryza sativa L.) Hibrida di Desa Ketaon Kecamatan Banyudono Boyolali. Skripsi. Fakultas Pertanian. Universitas Sebelas Maret.. 